Conclusions Voluntary fire brigade gives hope, new goals and empowerment to the vulnerable group of young people.

\section{IMPACT OF FIRST AID TRAINING ON THE FIRST AID KNOWLEDGE AND SKILLS CAPACITY OF PRIMARY SCHOOL TEACHERS IN IBADAN, NIGERIA}

${ }^{1}$ Abdulmumin Ibrahim, ${ }^{2}$ Nadia Sam-Agudu, ${ }^{1}$ Ugbede Omave, ${ }^{1}$ Boniface Ushie ${ }^{1}$ Adesola Olumide, ${ }^{1}$ Olayemi Omotade. ${ }^{1}$ University of Ibadan, Nigeria; 2 Institute of Human Virology Nigeria, Nigeria

\subsection{6/injuryprev-2016-042156.933}

Background Acute illness and injury are major causes of child morbidity and mortality. Young children are prone to injury, and schools in developing countries are often not optimally childproofed. In Nigeria, primary schoolteachers supervise students in an often injury-prone environment, with poor access to emergency services. First Aid (FA) can make a significant difference in outcome for a young child injured at school. This study was conducted to assess FA knowledge and skills in a cohort of primary school teachers and evaluate the effect of a training program on the cohort's FA capacity.

Methods We randomly selected 151 teachers from 16 primary schools in Ibadan. A 26-point survey and simulated scenarios graded on an 18-point scale assessed FA knowledge and skills, respectively. Based on identified gaps, a training program was developed and applied to a randomly selected subset of 70 of the 151 teachers, assigning them to intervention $(\mathrm{N}=36)$ and control $(\mathrm{N}=34)$. Controls were given an HIV education talk. FA knowledge and skills were measured immediately and 3 months post-intervention. FA knowledge was rated poor $(<13)$, fair $(13-$ $17)$ and good (>17); skills were rated poor $(<9)$, fair $(9-11)$ and good (>11). Chi-square, t-test and ANOVA were used to compare means and to test for associations.

Results Respondents' mean age was $41.44 \pm 9.90$ years, and 95.4\% had poor baseline knowledge. There was no difference in mean FA knowledge between intervention $(7.69 \pm 1.97)$ and control $(7.29 \pm 2.47)$ at baseline $(p=0.49)$. Mean baseline FA skills scores between intervention $(0.5 \pm 2.27)$ and control $(0.65 \pm 1.28)$ were similar $(\mathrm{p}=0.59)$. Compared to baseline, there was a significant increase in mean FA knowledge immediately $(20.83 \pm 1.00, \mathrm{p}<0.001)$ and 3 months post intervention $(18.24 \pm 2.00, \mathrm{p}<0.001)$. Mean FA skills scores also improved from baseline, immediately $(12.72 \pm 1.80, \mathrm{p}<0.001)$ and 3 months post intervention $(9.64 \pm 2.03, \mathrm{p}<0.001)$. There were no significant changes in FA knowledge or skills in the control group.

Conclusions First aid knowledge and skills among primary school teachers in Ibadan was poor. The training program led to a significant and sustained improvement in teachers' FA capacity. Primary school teachers can be trained and retrained to provide appropriate and timely basic care for students injured at school.

\section{INTERVENTIONS TO REDUCE INJURIES AMONG STUDENTS IN PRIMARY AND SECONDARY SCHOOLS IN XINING CITY}

Min-Ru Zhou, Su-Xia Zhou, Xu Zhi-Hua, Sha Qiong-Yue. QinHai Centre for Disease Prevention and Control, Qing Hai, China

10.1136/injuryprev-2016-042156.934
Background Injuries are a global public health problem, and child injuries are particularly outstanding considering that children are free from most other health problems. We carried out an investigation on injuries in three primary and two secondary schools in Xining in 2003, and the results showed that the incidence of injuries was as high as $26.24 \%$. Interventions were taken to reduce injuries in one primary and one secondary schools in Xining from 2006 to 2008.

Methods Baseline survey was carried out before intervention. School leaders, teachers, students, doctors and CDC experts were invited to devise intervention measures and discuss the implementation approaches. Between 2006 and 2008, several interventions were applied: dispensing injury prevention brochures; composing injury prevention knowledge into songs and printing them on school timetable; making posters of fall prevention; compiling the proposal of creating a safe and peaceful school environment and printing related contents on the outer packing of ballpoint pen; dispensing accidental childhood injury prevention handbook named "love, with safety first"; and sponsoring a drawing contest with the theme of injury prevention. Besides these measures, we also heightened and strengthened stair railings, placed warning signs on accident-prone locations, and improved school security.

Results The results of baseline survey showed that student knowledge awareness rate of fall injury prevention was $63.76 \%$; the overall incidence of injuries in students in one year was 21.51\%; and the leading types of injuries were fall (8.69\%), collision (3.85\%), traffic accident (2.14\%), burn (1.71\%), cut $(1.28 \%)$ and animal bites $(1.28 \%)$ according to the injury frequency. After intervention, the awareness rate of fall injury prevention in students increased to $98.86 \%$; the overall incidence of injuries decreased to $18.06 \%$; and the incidences of fall, collision, traffic accident, burn, cut and animal bites changed to $8.19 \%$, $3.03 \%, 1.82 \%, 1.52 \%, 1.37 \%$ and $0.91 \%$, respectively.

Conclusions Interventions could effectively reduce injuries among students. Our work laid a foundation for further interventions on child injuries in Xining city.

\section{SIGNIFICANCE OF TRADITIONAL MASCULINITY FOR THE PREDICTION OF INJURIES IN MALE ADOLESCENTS}

Natko Geres, Milan Milosevic, Aida Mujkić. University of Zagreb, School of Medicine, Andrija Stampar School of Public Health, Zagreb, Croatia

\subsection{6/injuryprev-2016-042156.935}

Background Risk from injuries and accidents is increased for men in comparison to women. Young men are especially at risk. There is a complexity of interactions between environmental and personal factors (masculinity, impulsivity, depression and indicators of socioeconomic status, micro and macro environment) in relation to risky behaviours and injuries and accidents. Men have higher incidence of risky behaviours (for instance, alcohol use) that contribute to injuries. Existing studies put emphasis on exploring traditional masculine attitudes as factors contributing to this trend.

Methods Research was implemented by using already existing, validated tools on 1. Injuries and accidents: Youth Risk Behaviour Survey-YRBS (CDC, 2013), 2. Masculinity: Male Role Norm Inventory- Adolescent- revised (MRNI-A-R), 3. Socioeconomic status: Indicators of socioeconomic status for adolescents using Family affluence scale as measure of family wealth and 4. Experiences of injuries and accidents using Injury Checklist )Jelalian, 